\title{
Origins of cancer: tackling provocative questions
}

\author{
Abigail R. Solitro ${ }^{1, *}$ and Nicole A. Vander Schaaf ${ }^{2, *}$ \\ ${ }^{1}$ Center for Cancer and Cell Biology, Van Andel Research Institute, Grand Rapids, MI, USA \\ ${ }^{2}$ Center for Epigenetics, Van Andel Research Institute, Grand Rapids, MI, USA \\ * These authors have contributed equally to this work \\ Correspondence to: Nicole A. Vander Schaaf, email: nicole.vanderschaaf@vai.org \\ Keywords: cancer, provocative questions initiative, microbiome, immunotherapy, biomarkers \\ Received: September 08, $2017 \quad$ Accepted: September 08, $2017 \quad$ Published: September 14, 2017
}

Copyright: Solitro et al. This is an open-access article distributed under the terms of the Creative Commons Attribution License (CC-BY), which permits unrestricted use, distribution, and reproduction in any medium, provided the original author and source are credited.

\section{ABSTRACT}

Despite the tremendous progress that scientists have made throughout the history of cancer research, there are still far too many deaths and remaining scientific questions for us to be content with our current knowledge of the disease. The eighth Origins of Cancer symposium, held July 21, 2017 at Van Andel Research Institute, was organized around the theme of "Tackling Provocative Questions" to stimulate discussion of several of these unresolved paradoxes in the field of cancer research. The symposium highlighted recent progress from the National Cancer Institute's Provocative Questions Initiative, a program that offers research support to scientists who propose innovative strategies to address one of the featured questions. Accordingly, each of our eight distinguished speakers had received funding through this Initiative or performs research that closely aligns with one of these important yet understudied questions. From microbes to biomarkers to immunotherapy, this meeting report describes the latest advancements that were presented at the symposium.

\section{INTRODUCTION}

The 2017 Origins of Cancer symposium pushed the boundaries of understudied and overlooked aspects of cancer research. The symposium boasted eight renowned clinicians and scientists whose research is funded by or closely aligns with the mission of the National Cancer Institute's (NCI's) Provocative Questions Initiative. Established by former National Institutes of Health (NIH) director, Dr. Harold Varmus, the Provocative Questions Initiative has sought to shed light on controversial, unanswered, and truly provocative questions in the cancer field since 2011 [1]. This year's symposium highlighted recent findings related to five of the provocative questions: (1) "what are the underlying molecular mechanisms that are responsible for the functional differences between benign proliferative diseases and premalignant states?"; (2) "how do microbiota affect the response to cancer therapies?"; (3) "how do variations in tumor-associated immune responses contribute to differences in cancer risk, incidence, or progression?"; (4) "what cancer models or other approaches can be developed to study clinically stable disease and the subsequent transition to progressive disease?"; and (5) "can we develop bifunctional small molecules that will couple oncoproteins or other cancercausing molecules of interest to inactivating processes such as degradation and achieve tissue-specific loss of function?"

The symposium began with an introduction and overview of the Provocative Questions Initiative by NCI's Program Director for the Initiative, Dr. Emily Greenspan. Dr. Greenspan shared that since 2011, the Initiative has received over 2,000 grant applications resulting in over 200 new R01 and R21 awards, totaling over \$200 million in research support. This success is attributed to the iterative cycle of question generation, evaluation, and revision, a process that includes both scientists and clinicians from multiple disciplines; frequent workshops are held around the world, hosting brainstorming sessions for experts in the cancer research field to debate the most important questions to be answered. Although the Initiative is still in its early years, recent evaluations of its success are promising. Dr. Greenspan shared that 30 of the 33 questions issued thus far have represented less than one percent of cancer literature, suggesting that these areas truly are understudied. In addition, over half 
of the questions' research areas saw an increase in cancer literature since the inception of the program. On average, each award funded by the Initiative has produced four publications, and these publications are cited twice as frequently as those not funded by the Initiative. Clearly, the NCI's support of innovative and creative research promises to benefit the cancer research community and ultimately, the individuals affected by these diseases.

\section{What are the underlying molecular mechanisms that are responsible for the functional differences between benign proliferative diseases and premalignant states?}

Following the introduction of the Initiative, the first provocative question that was addressed was, "what are the underlying molecular mechanisms that are responsible for the functional differences between benign proliferative diseases and premalignant states?" This question addresses the critical need for accurately diagnosing disease in order to prevent unnecessary or mistreatment of patients. Dr. Chetan Bettegowda (Johns Hopkins University School of Medicine) discussed his research using neurofibromatosis (NF) as a model of a benign proliferative disease that can advance to malignancy in the form of malignant peripheral nerve sheath tumors (MPNSTs). Dr. Bettegowda has shown that distinct, sequential mutations cause the progression of this disease; germline and subsequent somatic mutations in the NF1 gene lead to benign NF, and mutations in polycomb repressive complex 2 (PRC2) cause MPNSTs to arise from plexiform disease. Recently, Dr. Bettegowda's group uncovered the importance of SUZ12 mutations in this progression [2]. Interestingly, SUZ12 sits next to the NF1 gene on chromosome 17, and both are frequently lost in large deletion events. Dr. Bettegowda hopes to utilize these disease-associated mutations as biomarkers in NF patients. Using colorectal cancer (CRC) as a model, his team has shown that circulating tumor DNA can be collected, amplified, and used to determine the mutation status of the parent tumor $[3,4]$. Current research continues to apply this technique to patients with MPNSTs to inform treatment decisions.

Building off of Dr. Bettegowda's recent advances, Dr. Lisa Boardman (Mayo Clinic College of Medicine) discussed her research utilizing the progression of colon polyps to CRC as a model for addressing this provocative question. Dr. Boardman shared that the current standard for CRC screening is the colonoscopy, of which over six million are performed in the United States annually. She elaborated that about $25-40 \%$ of these procedures reveal polyps, but only about $10 \%$ of these polyps will progress to cancer. Unfortunately, the distinguishing features between polyps that progress to malignancy and those that remain benign are unknown. Dr. Boardman's group seeks to fill this gap in knowledge. Recently, Dr.
Boardman has collected tissue samples from CRC tumors, cancer-adjacent polyps, and cancer-free polyps in order to perform exploratory data analysis at the DNA, RNA, and epigenetic levels $[5,6]$. Several key findings have been elucidated from this work; while $K R A S$ and $A P C$ mutations are common among all three tissue groups, TP53 mutations are only present in tumors and canceradjacent polyps. In addition, global gene expression signatures distinguish tumors and cancer-adjacent polyps from cancer-free polyps, with CXCL5 expression elevated in the former, for example. Using reduced representation bisulfite sequencing, she also found that tumors and cancer-adjacent polyps tend to have more DNA methylation than cancer-free polyps. Dr. Boardman plans to continue investigating patient samples using various sequencing technologies, with the hope of integrating these data to create a panel of markers that will identify all patients whose polyps have the potential to progress to $\mathrm{CRC}$.

\section{How do microbiota affect the response to cancer therapies?}

In the second session, Drs. Scott Bultman (University of North Carolina at Chapel Hill) and Chrystal Paulos (Medical University of South Carolina) discussed the provocative question, "how do microbiota affect the response to cancer therapies?" The purpose of this question is to better understand the role of the microbiome in cancer, with the long-term goal of developing adjuvant therapies to enhance cancer treatment by targeting the microbiota. Dr. Bultman's talk focused on the microbial byproduct butyrate, a short-chain fatty acid and naturally occurring histone deacetylase (HDAC) inhibitor [7]. Butyrate is a bacterial fermentation product of fiber and is prevalent in the colon. Using the azoxymethane (AOM) and dextran sodium sulfate (DSS) mouse model of CRC, he found that colonizing the mice with butyrate-producing Butyrivibrio fibrisolvens reduces the tumor burden in mice on a high-fiber diet [8]. Neither a high-fiber diet alone nor colonization by a $B$. fibrisolvens mutant that cannot produce butyrate provides this tumor-suppressive effect. Interestingly, the impact of butyrate depends on the oxidative state of the target cell; normal colonic cells use butyrate as their primary energy source, so butyrate enhances their proliferation. In contrast, butyrate slows the proliferation of CRC cells, likely due to their shifted dependence on glucose because of the Warburg effect and consequent accumulation of the natural HDAC inhibitor [9]. These studies highlight the important role that microbial metabolites play in altering host physiology in both health and disease.

Dr. Chrystal Paulos presented her discovery that microbiota may explain how lymphodepletion enhances adoptive T cell transfer (ACT) therapy. For ACT therapy, $\mathrm{T}$ cells are removed from a patient and co-cultured ex vivo 
with the patient's own cancer cells. Cancer-reactive T cells are then selected, expanded, and returned to the patient, hopefully inducing a robust immune response against the cancer cells. When coupled with lymphodepletion (irradiation of the patient's immune cells), the efficacy of ACT therapy is enhanced, but the reasons for this are not well understood [10-13]. Dr. Paulos finds that treatment with the antibiotic Ciprofloxacin diminishes the benefit of lymphodepletion, suggesting that bacteria are partially responsible [14]. Her current working model is that lymphodepletion enhances ACT therapy through microbe-driven activation of the innate immune system. The radiation that is used for lymphodepletion damages the intestinal epithelial barrier and allows bacteria to penetrate regions where they are normally not permitted. This translocation activates innate immune cells, which foster the survival and activation of the re-introduced cancer-reactive T cells. Dr. Paulos hopes that these studies will reveal novel strategies to safely and effectively augment cancer immunotherapy.

\section{How do variations in tumor-associated immune responses contribute to differences in cancer risk, incidence, or progression?}

In the third session, Drs. Timothy Chan (Memorial Sloan Kettering Cancer Center) and Lyse A. Norian (University of Alabama at Birmingham) addressed the following question: "how do variations in tumorassociated immune responses contribute to differences in cancer risk, incidence, or progression?" This provocative question explores the factors that contribute to differential tumor-associated immune responses between patients, with the long-term goal of developing strategies to enable a patient's immune system to prevent or eradicate cancer. Dr. Chan uses computational strategies to identify molecular features that may help us understand why some patients respond to immunotherapy while others do not. He highlighted the importance of neoantigens (peptides that have undergone mutations that make them appear as foreign to the immune system) for achieving robust, cancer-targeted immune responses. Indeed, he found that mutational burden is predictive of response to anti-PD1 therapy in non-small cell lung cancer patients, with responsive patients having a higher average nonsynonymous mutation load than non-responders [15]. This trend holds true in several other cancers and may be a valuable tool for deciding a patient's treatment regimen. Recent studies, however, indicate that not all neoantigens are equal; for example, clonal neoantigens and possibly those resembling epitopes of pathogens appear to be more immunogenic [16-19]. Future studies will continue to explore how the mutational landscape and burden as well as neoantigen sequence and clonality contribute to the differential tumor-associated immune responses between patients.

Dr. Norian studies obesity as a risk factor for cancer and the impact that obesity has on immune responses in health and disease. Obesity increases the risk of 13 different types of cancer, but the precise mechanism is unknown [20]. Through her studies in mice with renal tumors, Dr. Norian finds that mice with diet-induced obesity respond poorly to cancer immunotherapy as compared to mice on a normal diet. Despite this phenotype, obesity does not significantly impact the development or maintenance of pre-existing or newly stimulated CD8 T cell responses [21]. However, Dr. Norian discovered that renal tumors from obese mice have enhanced accumulation of myeloid-derived suppressor cells, which are known to be immunosuppressive, and this recruitment is likely due to a higher intratumoral concentration of the myeloid cell-attractant CCL2 [22]. In this environment, dendritic cells have a reduced ability to activate T cells, which may help explain why obese mice have dampened responses to cancer immunotherapy. Dr. Norian hopes that these findings will enable scientists to develop dietary regimens or drugs that will enhance immune surveillance and responses to immunotherapy in cancer patients.

\section{What cancer models or other approaches can be developed to study clinically stable disease and the subsequent transition to progressive disease?}

The next provocative question that was addressed was, "what cancer models or other approaches can be developed to study clinically stable disease and the subsequent transition to progressive disease?" This question encourages the use of creative and nontraditional models that more closely mimic human disease. Dr. Christine Iacobuzio-Donahue (Memorial Sloan Kettering Cancer Center) utilizes autopsies as a means of modeling pancreatic cancer progression. Primary tumors, metastases and normal tissues such as blood, and cerebrospinal fluid are removed from deceased patients; tumors and metastases are then used to establish patientderived cell lines and xenograft mouse models. Her recent work has uncovered an incredible degree of mutational heterogeneity between different regions of the same tumor and/or metastasis [23]. At the same time, mutations in the four canonical pancreatic cancer-associated genes (KRAS, TP53, CDKN2A, and SMAD4) were consistently found in all tumors and metastases [24]. These unique mutational signatures have shown that local, recurring tumors are more similar to metastases than to the primary tumor, suggesting that metastases have the ability to seed tumor cells back into the pancreas after primary tumor resection. Dr. Iacobuzio-Donahue hopes to continue elucidating the importance of heterogeneity in pancreatic cancer in order to exploit it for therapeutic benefit to patients. 


\section{Can we develop bifunctional small molecules that will couple oncoproteins or other cancer-causing molecules of interest to inactivating processes such as degradation and achieve tissue-specific loss of function?}

The final speaker of this year's symposium was Dr. Craig Crews (Yale University) who shared his insight into the provocative question, "can we develop bifunctional small molecules that will couple oncoproteins or other cancer-causing molecules of interest to inactivating processes such as degradation and achieve tissuespecific loss of function?" The Crews lab has developed a "chemical equivalent of CRISPR" called PROTACs (proteolysis-targeting chimeras), small molecules that fuse ligands for a target protein to E3 ubiquitin ligase recognition domains [25]. The theory behind PROTACs is that oncogenic proteins or other cancer-causing molecules can be selectively targeted for degradation by the cell's own proteasome system. Dr. Crews has shown the success of PROTAC technology using the von HippelLindau E3 ubiquitin ligase recognition domain and several target proteins, including RIPK and ERR $\alpha$ [26, 27]. Of clinical importance, his recent work in mouse models suggests that PROTACs are orally available, tolerated, and effective [28]. Dr. Crews hopes to continue developing this technology for application to undruggable targets such as KRAS. This approach has the potential to revolutionize cancer therapy and is an exemplary illustration of using innovation to accomplish what was formerly deemed impossible.

The 2017 Origins of Cancer symposium successfully met its aim of providing a platform for discussion of unanswered and important questions in cancer research. From accurately diagnosing benign and malignant diseases to exploring the role of the immune system in cancer, these provocative topics are at the cutting edge of advancing our understanding of these diseases. The studies being performed by these eight scientists and their teams promise to impact not only their respective fields but also clinical care. We were honored to host them at this annual symposium and look forward to the stimulating discussion that awaits us at the next Origins of Cancer symposium, to be held at Van Andel Research Institute in July of 2018.

\section{ACKNOWLEDGMENTS}

First, we thank Dr. Mary Winn for her mentorship and guidance during our year-long professional development course on conference organization. We are especially thankful for Van Andel Research Institute's scientific events team, Beth Resau, Aubrie Bruinsma, and Kayla Habermehl, who played an invaluable role in planning, communicating with our speakers and sponsors, and promoting the event. We extend our thanks to the institutional advocates of this symposium, Drs. Peter Jones, Steve Triezenberg, and George Vande Woude. The event was generously hosted by Van Andel Research Institute. Financial support was provided by Van Andel Institute Graduate School, Amgen, Calvin College, Ferris State University, Michigan State University College of Human Medicine, and Spectrum Health Cancer Center. Finally, we thank our speakers and attendees for making this year's symposium a success.

\section{CONFLICTS OF INTEREST}

The authors declare that they have no competing interests.

\section{REFERENCES}

1. History | Provocative Questions [Internet]. [cited 2017 Aug 18]. Available 2017 Aug 18, from https:// provocativequestions.nci.nih.gov/about-pqs/history

2. Zhang M, Wang Y, Jones S, Sausen M, McMahon K, Sharma R, Wang Q, Belzberg AJ, Chaichana K, Gallia GL, Gokaslan ZL, Riggins GJ, Wolinksy J-P, et al. Somatic mutations of SUZ12 in malignant peripheral nerve sheath tumors. Nat Genet. 2014; 46: 1170-2. doi: 10.1038/ng.3116.

3. Bettegowda C, Sausen M, Leary RJ, Kinde I, Wang Y, Agrawal N, Bartlett BR, Wang H, Luber B, Alani RM, Antonarakis ES, Azad NS, Bardelli A, et al. Detection of circulating tumor DNA in early- and late-stage human malignancies. Sci Transl Med. 2014; 6: 224ra24. doi: 10.1126/scitranslmed.3007094.

4. Wang J, Bettegowda C. Applications of DNA-based liquid biopsy for central nervous system neoplasms. J Mol Diagn JMD. 2017; 19: 24-34. doi: 10.1016/j.jmoldx.2016.08.007.

5. Druliner BR, Rashtak S, Ruan X, Bae T, Vasmatzis N, O'Brien D, Johnson R, Felmlee-Devine D, WashechekAletto J, Basu N, Liu H, Smyrk T, Abyzov A, et al. Colorectal cancer with residual polyp of origin: a model of malignant transformation. Transl Oncol. 2016; 9: 280-6. doi: 10.1016/j.tranon.2016.06.002.

6. Druliner BR, Ruan X, Johnson R, Grill D, O’Brien D, Lai T-P, Rashtak S, Felmlee-Devine D, Washechek-Aletto J, Malykh A, Smyrk T, Oberg A, Liu H, et al. Time lapse to colorectal cancer: telomere dynamics define the malignant potential of polyps. Clin Transl Gastroenterol. 2017; 8: e88. doi: 10.1038/ctg.2017.16.

7. Chang PV, Hao L, Offermanns S, Medzhitov R. The microbial metabolite butyrate regulates intestinal macrophage function via histone deacetylase inhibition. Proc Natl Acad Sci. 2014; 111: 2247-52. doi: 10.1073/ pnas.1322269111.

8. Donohoe DR, Holley D, Collins LB, Montgomery SA, Whitmore AC, Hillhouse A, Curry KP, Renner SW, 
Greenwalt A, Ryan EP, Godfrey V, Heise MT, Threadgill DS, et al. A gnotobiotic mouse model demonstrates that dietary fiber protects against colorectal tumorigenesis in a microbiota- and butyrate-dependent manner. Cancer Discov. 2014; 4: 1387-97. doi: 10.1158/2159-8290.CD-14-0501.

9. Donohoe DR, Collins LB, Wali A, Bigler R, Sun W, Bultman SJ. The Warburg effect dictates the mechanism of butyrate-mediated histone acetylation and cell proliferation. Mol Cell. 2012; 48: 612-26. doi: 10.1016/j. molcel.2012.08.033.

10. Cheever MA, Greenberg PD, Fefer A. Specificity of adoptive chemoimmunotherapy of established syngeneic tumors. J Immunol Baltim Md 1950. 1980; 125: 711-4.

11. North, RJ. Cyclophosphamide-facilitated adoptive immunotherapy of an established tumor depends on elimination of tumor-induced suppressor T cells. J Exp Med. 1982; 155: 1063-74.

12. Dudley ME, Wunderlich JR, Yang JC, Sherry RM, Topalian SL, Restifo NP, Royal RE, Kammula U, White DE, Mavroukakis SA, Rogers LJ, Gracia GJ, Jones SA, et al. Adoptive cell transfer therapy following non-myeloablative but lymphodepleting chemotherapy for the treatment of patients with refractory metastatic melanoma. J Clin Oncol Off J Am Soc Clin Oncol. 2005; 23: 2346-57. doi: 10.1200/ JCO.2005.00.240.

13. Wrzesinski C, Paulos CM, Kaiser A, Muranski P, Palmer DC, Gattinoni L, Yu Z, Rosenberg SA, Restifo NP. Increased intensity lymphodepletion enhances tumor treatment efficacy of adoptively transferred tumor-specific T cells. J Immunother Hagerstown Md 1997. 2010; 33: 1-7. doi: 10.1097/CJI.0b013e3181b88ffc.

14. Paulos CM, Wrzesinski C, Kaiser A, Hinrichs CS, Chieppa M, Cassard L, Palmer DC, Boni A, Muranski P, Yu Z, Gattinoni L, Antony PA, Rosenberg SA, et al. Microbial translocation augments the function of adoptively transferred self/tumor-specific CD8 $+\mathrm{T}$ cells via TLR4 signaling. J Clin Invest. 2007; 117: 2197-204. doi: 10.1172/ JCI32205.

15. Rizvi NA, Hellmann MD, Snyder A, Kvistborg P, Makarov V, Havel JJ, Lee W, Yuan J, Wong P, Ho TS, Miller ML, Rekhtman N, Moreira AL, et al. Mutational landscape determines sensitivity to PD-1 blockade in non-small cell lung cancer. Science. 2015; 348: 124-8. doi: 10.1126/ science.aaa1348.

16. Snyder A, Makarov V, Merghoub T, Yuan J, Zaretsky JM, Desrichard A, Walsh LA, Postow MA, Wong P, Ho TS, Hollmann TJ, Bruggeman C, Kannan K, et al. Genetic basis for clinical response to CTLA-4 blockade in melanoma. $\mathrm{N}$ Engl J Med. 2014; 371: 2189-99. doi: 10.1056/ NEJMoa1406498.

17. McGranahan N, Furness AJS, Rosenthal R, Ramskov S, Lyngaa R, Saini SK, Jamal-Hanjani M, Wilson GA, Birkbak NJ, Hiley CT, Watkins TBK, Shafi S, Murugaesu N, et al. Clonal neoantigens elicit $\mathrm{T}$ cell immunoreactivity and sensitivity to immune checkpoint blockade. Science. 2016;
351: 1463-9. doi: 10.1126/science.aaf1490.

18. Riaz N, Morris L, Havel JJ, Makarov V, Desrichard A, Chan TA. The role of neoantigens in response to immune checkpoint blockade. Int Immunol. 2016; 28: 411-9. doi: 10.1093/intimm/dxw019.

19. Morris LGT, Riaz N, Desrichard A, Şenbabaoğlu Y, Hakimi AA, Makarov V, Reis-Filho JS, Chan TA. Pancancer analysis of intratumor heterogeneity as a prognostic determinant of survival. Oncotarget. 2016; 7: 10051-63. doi: 10.18632/oncotarget.7067.

20. Lauby-Secretan B, Scoccianti C, Loomis D, Grosse Y, Bianchini F, Straif K. Body fatness and cancer - viewpoint of the IARC working group. N Engl J Med. 2016; 375: $794-$ 8. doi: 10.1056/NEJMsr1606602.

21. Khan SH, Hemann EA, Legge KL, Norian LA, Badovinac VP. Diet-induced obesity does not impact the generation and maintenance of primary memory CD8 T cells. J Immunol Baltim Md 1950. 2014; 193: 5873-82. doi: 10.4049/jimmunol.1401685.

22. Hale M, Itani F, Buchta CM, Wald G, Bing M, Norian LA. Obesity triggers enhanced MDSC accumulation in murine renal tumors via elevated local production of CCL2. PLOS ONE. 2015; 10: e0118784. doi: 10.1371/journal. pone. 0118784

23. Perry EB, Makohon-Moore A, Zheng C, Kaufman CK, Cai J, Iacobuzio-Donahue CA, White RM. Tumor diversity and evolution revealed through RADseq. Oncotarget. 2017; 8: 41792-805. doi: 10.18632/oncotarget.18355.

24. Makohon-Moore AP, Zhang M, Reiter JG, Bozic I, Allen B, Kundu D, Chatterjee K, Wong F, Jiao Y, Kohutek ZA, Hong J, Attiyeh M, Javier B, et al. Limited heterogeneity of known driver gene mutations among the metastases of individual patients with pancreatic cancer. Nat Genet. 2017; 49: 358-66. doi: 10.1038/ng.3764.

25. Neklesa TK, Winkler JD, Crews CM. Targeted protein degradation by PROTACs. Pharmacol Ther. 2017; 174: 138-44. doi: 10.1016/j.pharmthera.2017.02.027.

26. Ottis P, Toure M, Cromm PM, Ko E, Gustafson JL, Crews CM. Assessing different E3 ligases for small moleculeinduced protein ubiquitination and degradation. ACS Chem Biol. 2017. doi: 10.1021/acschembio.7b00485.

27. Lu J, Qian Y, Altieri M, Dong H, Wang J, Raina K, Hines J, Winkler JD, Crew AP, Coleman K, Crews CM. Hijacking the E3 ubiquitin ligase cereblon to efficiently target BRD4. Chem Biol. 2015; 22: 755-63. doi: 10.1016/j. chembiol.2015.05.009.

28. Schneekloth JS, Fonseca FN, Koldobskiy M, Mandal A, Deshaies R, Sakamoto K, Crews CM. Chemical genetic control of protein levels: selective in vivo targeted degradation. J Am Chem Soc. 2004; 126: 3748-54. doi: $10.1021 /$ ja039025z. 